\title{
Libertad religiosa, educación y menores de edad*
}

\author{
Deivys Javier Pabón Medina ${ }^{1}$
}

* El presente capítulo es producto de investigación de los estudios del Doctorado en Sostenibilidad y Paz en la Era Posglobal, realizados en la Universidad de Valencia España, concluidos en diciembre de 2016, bajo la dirección del Dr. August Monzon i Arazo.

1 Doctor en Sostenibilidad y Paz en la era Posglobal. Máster en Derechos Humanos, Paz y Desarrollo Sostenible en la Universidad de Valencia, España. Licenciado en Teología por la Universidad Católica Santa Rosa (Caracas). Investigador en el campo de los derechos humanos y globalización, justicia, democracia, ciudadanía y derechos, igualdad y no discriminación y protección internacional de los derechos humanos y operaciones de mantenimiento de la paz. Secretario Canciller y Jefe de Recursos Humanos del Ordinariato Militar para Venezuela. Grupo de Investigación de Economía Social de la Universidad Católica de Valencia, España.

Correo: deivysja@gmail.com 


\title{
RESUMEN
}

El texto se enmarca en el debate actual de los derechos humanos. Desde una perspectiva teórica se subrayan los conceptos de libertad y libertad religiosa, de acuerdo con algunos instrumentos internacionales. Enmarcamos el caso educativo de Lautsi vs Italia en referencia a los crucifijos en las escuelas.

Palabras clave: libertad, libertad religiosa, derechos humanos, paz, educación, menor de edad.

\section{RELIGIOUS FREEDOM, EDUCATION AND MINORS}

\begin{abstract}
The text is framed in the current debate on human rights. From a theoretical perspective, the concepts of freedom and religious freedom are emphasized, according to some International Instruments. We frame the educational case of "Lautsi vs. Italy" in reference to crucifixes in schools.
\end{abstract}

Keywords: freedom, religious freedom, human rights, peace, education, minor.

\section{INTRODUCCIÓN}

No es un tema fácil porque a los problemas que de por sí genera el ejercicio del derecho por sujetos que no tienen plena madurez en el campo intelectual, emocional o volitivo, se suman los nuevos conflictos que generan hoy día las diversas pautas culturales y religiosas presentes en nuestra sociedad como consecuencia de diferentes factores, entre ellos el migratorio. Los problemas se acentúan si se sitúa al adolecente o menor de edad y sus creencias religiosas en el ámbito de la salud, ya que entran en juego otros bienes jurídicos como la vida, la integridad física y moral, la salud o la intimidad personal, que agudizan los conflictos e impiden apuntar soluciones razonables. La mayor parte de los ordenamientos jurídicos dividen el curso de la vida humana en dos únicas etapas, la mayor y la menor 
edad, y fijan la mayoría de edad en los 18 años, que es la frontera o línea divisoria de la plena capacidad de obrar de la persona en el goce de todos sus derechos, civiles, políticos y sociales ${ }^{2}$. Por eso, a efectos del derecho, es menor todo ser humano que no ha cumplido la edad de 18 años, incluyéndose dentro del término tanto al niño, como al adolescente, $\mathrm{y}$ al joven menor de edad se le concibe hoy como en un periodo temporal más en la existencia de la persona que se caracteriza por «la doble consideración del menor como sujeto autónomo de derechos y, a la vez, como ser humano en formación, merecedor de protección por parte del ordenamiento jurídico». Así lo proclama la convención sobre los derechos del niño de 20 de noviembre de $1989^{3}$ y así lo reconoce la Ley 1/1996, de Protección Jurídica del menor ${ }^{4}$, cuya exposición de motivos conceptúa a los menores como «sujetos activos, participativos y creativos, con capacidad de modificar su propio medio personal y social; de participar en la búsqueda y satisfacción de sus necesidades y en la satisfacción de las necesidades de los demás».

Profundizaremos sobre el concepto de libertad, libertad religiosa, pero el enfoque principal será en el ámbito educativo.

\section{APROXIMACIÓN A LA LIBERTAD RELIGIOSA}

\section{Concepto de libertad}

El concepto de libertad es sumamente complejo y múltiples han sido (y son) sus interpretaciones, como nos recuerda Ferrater Mora en su diccionario de filosofía:

Algunos modos como se ha entendido el concepto de libertad: como posibilidad de autodeterminación; como posibilidad de elección; como acto

2 Cfr. Álvarez Vélez, Ma. (1994). La protección de los derechos del niño en el marco de las Naciones Unidas y en el Derecho Constitucional español, Madrid, 1994, p.104.

3 Es el instrumento internacional de mayor relevancia en la promoción y defensa de los derechos de los niños porque tiene carácter vinculante para los estados firmantes y porque recoge un amplio elenco de derechos de los menores y de correlativas obligaciones que deben asumir los estados que se adhieran a él.

4 Disponible en https:/www.boe.es/buscar/doc.php?id=BOE-A-1996-1069. Consulta 02/06/2017. 
voluntario; como espontaneidad; como margen de indeterminación; como ausencia de interferencia; como liberación frente a algo; como liberación para algo; como realización de una necesidad. Junto a ello el concepto en cuestión ha sido entendido de diversos modos según la esfera de acción o alcance de la libertad; así, se ha hablado de libertad privada o personal; libertad pública; libertad política; libertad social; libertad de acción; libertad de palabra; libertad de idea; libertad moral, etc., etc. (1958, p. 49)

A la palabra libertad subyace un mundo de significados y perspectivas profundas que están conectados al sentimiento volitivo, al sentido de la dignidad humana y también al mundo espiritual, ya que se relaciona con el macrouniverso cultural-religioso: no es fácil minimizar su definición y al mismo tiempo abarcar la extensión de su significado.

Recordando a Montesquieu: "no hay palabra que haya recibido significados tan diferentes ni impresionado las imaginaciones de modos tan distintos como la de libertad" (Montesquieu, 1906, p.223). Lo entendieron también muchos otros pensadores quienes, a partir de las primeras especulaciones alrededor del concepto originariamente expresado por el término latín liber ('libre'), la referían al sentido de "persona en la cual el espíritu de procreación se halla naturalmente activo" (Ferrater Mora, 1958, p.49), pero el reconocimiento de tal capacidad además tenía otros significados. Representaba la entrada "a la comunidad como hombre capaz de asumir responsabilidades. [...] En este sentido el hombre libre es el que es de condición no sometida o esclava" (p.49) y de igual manera en el pensamiento griego se utilizaba "el término $\mathbf{\varepsilon} \lambda \boldsymbol{\varepsilon v ́} \boldsymbol{\theta} \boldsymbol{\varepsilon \rho o} \varsigma$ en un sentido parecido al que tenía liber entre los romanos" (p.49).

La complejidad del concepto de libertad se revela también durante la historia de la filosofía, cuando otros pensadores, en el intento de definirlo, reflexionaron acerca de su extensión interpretativa, decidiendo recurrir a definiciones por comparación o por contraste con otros términos y que per- 
tenecían a otras esferas de la acción humana: por eso, albedrío, autonomía, buena voluntad, conciencia, moral, deber, determinación, determinismo, indeterminismo, indiferencia o voluntad, por decir algunos, están muy relacionados con el concepto de libertad.

No entraremos en los detalles del análisis de cada uno de estos posibles modelos explicativos, pero lo que sí haremos ahora es señalar el elemento que tienen en común: parece que el desarrollo del concepto de libertad se despliega a partir de dos dimensiones, una del "poder hacer" y otra que introduzca algún tipo de limitación.

Pero, ¿qué es la libertad o por lo menos qué es lo que entendemos legalmente con ella, ya que se aplica en diferentes esferas de la conducta humana?

Vamos por orden y veamos qué entiende y establece la legislación española acerca de la disposición del ser humano a ser libre, antes de analizarla según otras perspectivas. El artículo 16 de la Constitución Española declara:

1. Se garantiza la libertad ideológica, religiosa y de culto de los individuos y las comunidades sin más limitación, en sus manifestaciones, que la necesaria para el mantenimiento del orden público protegido por la ley.

2. Nadie podrá ser obligado a declarar sobre su ideología, religión o creencias.

3. Ninguna confesión tendrá carácter estatal. Los poderes públicos tendrán en cuenta las creencias religiosas de la sociedad española y mantendrán las consiguientes relaciones de cooperación con la Iglesia Católica y las demás confesiones. 
El texto data de 1978 y la cuestión fue sucesivamente desarrollada ${ }^{5}$, aunque estamos sobre todo en un contexto de reglamentación de las relaciones Estado-Iglesia y no tanto en un campo de los derechos humanos. Un avance en tal dimensión, empezó en el 2008 con el Plan General de Derechos Humanos del Gobierno de España ${ }^{6}$, y en específico en el apartado dedicado a la Acción Interior, cuando en su número 4, se refiere a la "Libertad religiosa", estableciendo además lo siguiente en la Medida 70: "El Gobierno aprobará un proyecto de ley de reforma de la Ley Orgánica de Libertad Religiosa, recogiendo la jurisprudencia constitucional sobre la materia" (p.26).

Sea mencionado el valor constitucional español reconocido a la libertad ideológica, religiosa y de culto (sin entrar en el mérito de las sucesivas modificaciones y ampliaciones legislativas) y ahora parece interesante citar también su significado lexical, definido como la "facultad natural que tiene el hombre de obrar de una manera o de otra, y de no obrar, por lo que es responsable de sus actos" y también el específicamente religioso, es decir la "libertad de conciencia y de cultos" (Diccionario de la RAE, 2014).

Se puede intuir cómo nuestras suposiciones acerca de la amplitud del concepto de libertad, confirmadas por la misma Constitución y por la Real Academia Española, nos ayudan a comprender cómo la libertad pertenece y subyace a la individualidad humana. El precepto constitucional español, sin embargo, otorga unas limitaciones al concepto de libertad, "sin más limitación, en sus manifestaciones, que la necesaria para el mantenimiento del orden público protegido por la ley"; en otras palabras, justifica una acción coercitiva del Estado en vista de un bien común, garantizado y protegido por ley, el orden público.

Estas preliminares consideraciones no ayudan todavía a la comprensión

5 Ley Orgánica 7/1980, de 5 de julio, de Libertad Religiosa. Boletín Oficial del Estado, 177, de 24 de julio de 1980.

6 Plan General de Derechos Humanos del Gobierno de España, de 12 de diciembre de 2008, núm. IV, 4. Recuperado de http://www.ohchr.org/Documents/Issues/NHRA/Spain_NHRAP.pdf [Consulta: 07/05/2016]. 
y definición de esta facultad, por eso el concepto de libertad necesita mayores atenciones para poderlo entender apropiadamente y creemos se debe empezar pasando por las conceptualizaciones inherentes a la Filosofía Política, empezando por su definición, según Audi:

Estudio de la naturaleza y justificación de las instituciones coercitivas. Las instituciones coercitivas van según su tamaño de la familia al Estado y las organizaciones mundiales, como las Naciones Unidas [...] La justificación de tales instituciones coercitivas exige mostrar que sus autoridades tienen derecho a la obediencia y sus miembros el deber correlativo de obediencia; es decir, que tales instituciones tienen una autoridad legítima sobre sus miembros, (2004, p.420).

El estudio de la naturaleza y justificación de las instituciones coercitivas, nació con los filósofos políticos clásicos, como Platón y Aristóteles, aunque sus consideraciones se plantaban en la justificación de la forma política de las ciudades-Estado (por ejemplo, Atenas o Esparta). Sin embargo, durante todo el largo recorrido histórico, a medida que la exigencia de instituciones coercitivas deviniera necesaria (o se conseguía), mayormente los filósofos políticos se empeñaban para justificarla, llegando también a considerar distintas formas de gobierno mundial.

Por ende, se proponían justificar las instituciones coercitivas, tanto que, en respuesta al nacimiento de las modernas naciones-Estado, se llegó a la apología del monopolio del ejercicio de poder de coerción y se formó una escuela de pensamiento, el liberalismo, doctrina en principio elaborada por el filósofo inglés John Locke ${ }^{7}$, que las justificaba en vista del desarrollo de la libertad e intentos en demostrar que "la monarquía constitucional

7 Locke, J. (1632-1704), filósofo inglés considerado precursor del empirismo con su Ensayo sobre el entendimiento humano, al conceder protagonismo a las percepciones sensoriales sobre las esencias metafísicas. Desarrolla el pensamiento político liberal en sus Dos tratados sobre el gobierno, uno de cuyos pilares básicos consiste en la tolerancia civil en materia religiosa. Sobre este tema escribió una Carta sobre la tolerancia en la que argumenta la incapacidad del poder civil para juzgar asuntos religiosos, y reivindica la libertad de conciencia frente a la autoridad del Estado. En polémica son Jonas Proast anglicano de Oxfort, escribirá otras tres cartas para defender su opinión sobre la tolerancia civil. 
asegura la libertad, sosteniendo que los seres libres e iguales en un estado de naturaleza elegirían ese gobierno con el fin de preservar su libertad y sus propiedades" (Audi, 2004, p.606).

La justificación del derecho del Estado a ejercer el poder coercitivo, se funda en un importante concepto político jurídico, la soberanía, que como recuerdan tres importantes politólogos italianos, Bobbio, Matteucci y Pasquino:

Sirve para indicar el poder de mando en última instancia en una sociedad política y, por consiguiente, para diferenciar a ésta de las otras asociaciones humanas, en cuya organización no existe tal poder supremo [...] la soberanía pretende ser una racionalización jurídica del poder, en el sentido de transformar la fuerza en poder legítimo, el poder de hecho en poder de derecho. (2005, p.148)

Con la racionalización jurídica del poder, se justifica la consecuente legitimación del manejo de la fuerza por parte del Estado, y la clásica formulación de la definición de soberanía ${ }^{8}$ por parte del filósofo político francés Bodino, puesta a la base de pensamiento político de Hobbes, hace entender su extensión:

La soberanía es el poder absoluto y perpetuo de una república $[\ldots]$ Habiendo dicho que la república es un recto gobierno de varias familias, y de lo que les es común [...] este poder es perpetuo, puesto que puede ocurrir que se conceda poder absoluto a uno o a varios por tiempo determinado, los cuales, una vez transcurrido éste, no son más que súbditos. Por tanto, no puede llamárseles príncipes soberanos cuando osténten tal poder, ya que sólo son sus custodios o depositarios, hasta que place al pueblo o al príncipe revocarlos. Es éste quien permanece siempre en posesión del poder. (1997, pp.120-121)

8 Cf. Carrillo Salcedo, J. A. (1976). Soberanía del Estado y Derecho Internacional, Madrid: Tecnos, pp. 365-385.

\section{4}


El príncipe, el depositario del poder soberano, según Bodino tiene que gozar de una condición privilegiada en cara a las leyes y no ser sujeto a ellas, es decir, defender el poder absoluto. Por tanto, señala:

Si decimos que tiene poder absoluto quien no está sujeto a las leyes, no se hallará en el mundo príncipe soberano, puesto que todos los príncipes de la tierra están sujetos a las leyes de Dios y de la naturaleza y a ciertas leyes humanas comunes a todos los pueblos. Y al contrario, puede suceder que uno de los súbditos esté dispensado y exento de todas las leyes, ordenanzas y costumbres de su república [...] siempre queda bajo la obediencia y sujeción de quienes detentan la soberanía. Es necesario que quienes son soberanos no estén de ningún modo sometidos al imperio de otro y puedan dar ley a los súbditos y anular o enmendar las leyes inútiles; esto no puede ser hecho por quien está sujeto a las leyes o a otra persona. Por esto, se dice que el príncipe está exento de la autoridad de las leyes. [Legibus solutus] (1997, pp.125-126)

Además del liberalismo lockiano hubo, a lo largo del tiempo, otras distinciones doctrinales del ideal de libertad, aunque se puedan distinguir por lo menos dos grandes corrientes: el liberalismo clásico, cercano al pensamiento de Locke, y el liberalismo del bienestar, una forma de liberalismo que recoge la doctrina de Thomas Hill Green.

La diferencia distintiva entre las dos corrientes se refiere, según Audi (2004), a la interpretación de las limitaciones de la libertad, como "actos positivos", o que también incluyen "actos negativos":

El liberalismo clásico, que hoy en día es llamado con más frecuencia libertarismo (político) [...] interpreta las limitaciones de la libertad como actos positivos (es decir, actos de comisión) que impiden que la gente haga lo que de otro modo podría hacer. Según esta concepción, no ayudar a la gente que lo necesita no restringe su libertad [...]. Por el contrario, para el liberalismo del bienestar [...] las limitaciones de la libertad incluyen además actos 
negativos (es decir, actos de omisión) que impiden que la gente haga lo que de otro modo podría hacer. Según esta concepción, no ayudar a la gente necesitada restringe su libertad. (p. 420)

Estas dos diferentes tipologías de aproximación a la libertad, se distinguen también en distintas intrusiones coercitivas del Estado; para los liberales clásicos, "sólo un Estado mínimo que proteja frente al uso de la fuerza, el robo y el fraude puede estar justificado", mientras para los liberales del bienestar, sólo lo estaría "un Estado del bienestar que exige un mínimo social garantizado e igualdad de oportunidades" (p.420).

Esta rápida y no exhaustiva reseña de la interpretación de las limitaciones de la libertad, muestra cómo tal problemática se coloca en el centro de interés de las especulaciones acerca del estudio de la naturaleza y justificación de las instituciones coercitivas, pero la filosofía política no puede abarcar por sí sola la totalidad del concepto de libertad, y tanto menos el de libertad religiosa, porque sería oportuna una aproximación multidisciplinaria que tuviera en cuenta de la complexidad de esta facultad humana, o capacidad de actuar según una propia decisión, ya que se quiere extenderlo a derecho humano.

Pero, ¿hay solo un tipo de libertad o cuántas son sus posibles interpretaciones?

Sea expuesta la pluralidad interpretativa del término libertad, subrayando el elemento en común entre ellas, la duplicidad de dirección, la de "poder hacer" y la de "poder no hacer" por causa de algún tipo de limitación, y por eso las especulaciones de los filósofos políticos se centraron en la justificación del poder coercitivo estatal.

Todo esto significa que en términos generales, podemos también definir la libertad como facultad del ser humano de actuar o no actuar según su 
propia voluntad y siendo responsable de su propia conducta; en otras palabras, la voluntad que permite al individuo la elección o autodeterminación.

Manteniendo la dúplice conceptualización hasta ahora expuesta, podemos considerar otra diferenciación, distinguiendo entre las dos grandes esferas de dominio de la libertad, las cuales pueden ser restringidas o impedidas: la positiva y la negativa, "respectivamente, ámbito en el que el individuo es auto-determinante y ámbito en el que el individuo está libre de las interferencias de los demás" (p.607).

La libertad positiva se refiere a la autonomía humana, es decir al dominio que tenemos sobre nuestras vidas o al dominio de uno mismo y puede encontrar impedimentos internos por parte de los deseos y de las pasiones.

La libertad que corresponde al sentido negativo ${ }^{9}$, representa la falta de impedimentos extraños a nuestra voluntad; en otras palabras, se condiciona por restricciones externas porque nuestras limitaciones derivan de otros.

Los dos sentidos interpretativos de la libertad encontraron los favores de los filósofos, respectivamente de Platón, Espinoza, Rousseau, Kant y Hegel por cuanto concierne a la libertad positiva, y de Hobbes, Locke y Hume a la negativa.

\section{CONCEPTO DE LIBERTAD RELIGIOSA}

Se ha intentado explicar el concepto de libertad, aunque haciéndolo en modo sumario respecto a la extensión de la noción, la cual merecería un análisis más exhaustivo, sin embargo haremos algo a resguardo, distinguiendo la libertad religiosa, un tema de gran actualidad que tuvo una relevancia significativa a partir de la novedad de la cultura cristiana. La

9 El término "libertad negativa" fue utilizado por el filósofo moral y de la política Jeremy Bentham (1748-1832) para referirse a la ausencia de coacción. 
continuidad presencial de la problemática religiosa en la dimensión social humana, fue expresada claramente en el epílogo de Filoramo, Massenzio, Raveri y Scarpi:

De hecho, es precisamente en el ámbito de lo social, de lo público y de lo colectivo, del que los procesos de secularización parecen haberlas excluido definitivamente, donde las religiones parecen destinadas a conservar su papel significativo; ya sea por su capacidad simbólica, en la época de la fluidez de los no lugares, de definir y trazar límites, de marcar espacios, de circunscribir lugares; ya sea, por el contrario, por su carácter dinámico y por su experiencia misionera de «religiones sin frontera», por su capacidad de integración y de apertura a la confrontación, al diálogo, a la promoción de valores tan absolutamente indispensables como la paz; ya sea, por último, por su condición de espacios sagrados y de identificación de la memoria colectiva, que permiten escapar del aguijón angustioso del eterno presente de la cotidianidad. (2000, p.418)

Explicaremos en seguida qué se entiende con el término secularización (Dobbelaere, 1981), pero no antes de introducir una nueva tipología interpretativa del concepto de libertad religiosa, la cual creemos introducida a partir de la novedad del hecho cristiano. Precisamos nuestras intenciones, porque no queremos decir que el sentimiento de libertad religiosa no haya sido manifestado anteriormente, sino solo que a través de la figura de Jesucristo y de sus seguidores adquiere otra dimensión, despliega todo su poderío, y en particular modo queremos referirnos al concepto de martirio, a las vidas inmoladas en defensa de una $\mathrm{fe}^{10}$ que nos recuerdan hasta dónde está dispuesto a llegar el hombre en la defensa de su propia libertad religiosa.

10 Disponemos de sólidos y antiguos alegatos, una serie de documentos denominados "Acta Martyrum", distinguibles del "Acta Alexandrinorum" o Actas de los mártires paganos, en que se relatan los procesos judiciales y el martirio infligido a cristianos por su fe, aunque en la mayoría de los casos, no se conozca sean documentos oficiales de magistrados imperiales, que fueron utilizados como fuente en alguna ocasión. Véase el parágrafo $\mathrm{V}$ del capítulo I de El cristianismo primitivo en la sociedad romana de Ramón Teja (1990). 
El concepto de mártir es muy relevante en el contexto de la libertad religiosa, porque nos permite entender el dominio de la voluntad humana en el cumplimiento de la mayor extensión posible de ella, es decir, entregar la vida por una causa y también porque sería lícito afirmar que los mártires cristianos introducen una nueva libertad, referida a la experiencia divina o religiosa.

No sorprende que el término griego martys esté a indicar el 'testigo', el 'testimonio de los propios convencimientos hasta la muerte; por eso hablamos de extremo valor de la voluntad humana, y las palabras de Orígenes (s. III), en su Comentario sobre el Evangelio de Juan, nos ayudan en la comprensión:

Quien da testimonio de la verdad, ya con palabras ya con actos, tiene derecho a ser llamado mártir; pero entre los hermanos, llevados por su amor a los que lucharon hasta la muerte, se ha establecido la costumbre de llamar mártires a quienes testimoniaron en favor del misterio de la piedad con la efusión de su sangre. (In Joan. II, pp.14,176)

Gracias a los Padres de la Iglesia ${ }^{11}$, entendemos que a la palabra corresponda un dúplice sentido, uno general, donde mártir es un testigo de la verdad y otro más específico y establecido de común acuerdo, donde es un testigo sangrante, es decir, añadiendo la dimensión de muerte que comúnmente le acompaña.

Las conclusiones de Ropero (2010) mostradas en su obra histórica de las persecuciones, nos ayudan en la comprensión:

En resumen, el cristiano mártir es el testigo de la vida sobrenatural de Cristo que habita en su interior. Habla por experiencia y por eso pone su experiencia al servicio de la verdad, hasta el punto de la entrega suprema si

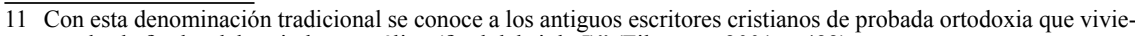
ron desde finales del periodo apostólico (final del siglo I)" (Filoramo, 2001, p.422). 
necesario. Por medio del sacrificio los mártires testifican la real existencia de Cristo que viven en el espíritu y de la existencia que les aguarda en la otra vida. No tienen nada que temer, pues quien les arrebata la vida del cuerpo no les puede arrebatar la vida del alma. (Mt, 10, 28, p.27)

Por consiguiente, se cree que entonces parezcan justificadas las consideraciones acerca de la complejidad interpretativa del concepto (y del sentimiento) de libertad, y por eso, en vista de un mejor entendimiento de la específica libertad religiosa a través de la experiencia del martirio, juzgamos apropiado considerar las vicisitudes de Jesús llamado "el testigo (mártir) fiel y verdadero" en Ap 3,1 que constituyen la máxima representación del modelo ${ }^{12}$ en cuestión.

La experiencia terrenal de Jesús representa un caso único en su género, ya que su martirio fue permanente, y definido por Iraburu de esta manera:

[...] Jesucristo es mártir permanente de Dios en el mundo. [...] Él es mártir no solo en cuanto testigo continuo de la verdad de Dios, es decir, como profeta, sino también lo es durante toda su vida en el sentido doloroso que este término tiene en la tradición cristiana. En efecto, durante toda su vida en la tierra, Cristo avanza consciente, libre y amorosamente hacia la Cruz. (2003, p.2)

La distinguida y permanente condición de Cristo, no muestra aún y en modo evidente la nueva libertad cristiana la cual estábamos comentando, al nuevo valor interpretativo de la voluntad humana; en otras palabras, la nueva elección volitiva religiosa ofrecida a los hombres por Jesús; para comprenderla, citaremos el Evangelio de Marcos:

Y llamando a la gente y a sus discípulos, les dijo: Si alguno quiere venir en pos de mí, niéguese a sí mismo, y tome su cruz y sígame. Porque el que

12 Véase, por profundizar el concepto de modelo psicológico, la teoría de los modelos mentales de Philip Johnson-Laird acerca de la modalidad representativa de la realidad. Entrevista a Philip N. Johnson-Laird (1988). Disponible en dialnet.unirioja.es/descarga/articulo/2664624.pdf [Consulta: 14/11/2015]. 
quiera salvar su vida la perderá; pero el que pierda su vida por causa de mí y del evangelio la salvará. (Mc 8, 34-35)

Aquí está la comprensión de la que consideramos la nueva tipología de libertad religiosa ofrecida por Jesús, la elección por ser testimonio de una verdad, Vía Crucis del martirio que conscientemente, libremente, voluntariamente y amorosamente lleva a la muerte. Un acto volitivo entre un camino martirial y mortal que lleva a la vida eterna o un falso camino que la evita eligiendo una muerte terrenal.

Los mártires cristianos ${ }^{13}$ nos convencen en esta perspectiva y el alegato del evangelista Lucas en los Hechos, testimonia el primer martirio de un cristiano, un tal Esteban, condenado a la lapidación tras enfurecer a los sacerdotes del Sanedrín, mostrando el descuido del joven por el sufrimiento infligido y la sabiduría de su fe:

$\mathrm{Y}$ oyendo estas cosas, se enfurecían sus corazones y crujían los dientes contra él. Pero Esteban, estando lleno del Espíritu Santo, [...] dijo ¡He aquí, veo los cielos abiertos y al Hijo del Hombre que está a la diestra de Dios! Entonces ellos, [...] arremetieron a una contra él; y echándolo fuera de la ciudad, le apedrearon. Y los testigos pusieron sus ropas a los pies de un joven que se llamaba Saulo. Y mientras apedreaban a Esteban, él invocaba y decía: Señor Jesús, recibe mi espíritu. Y puesto de rodillas, clamó a gran voz: Señor, no les tengas en cuenta este pecado. Y habiendo dicho esto, durmió. (Hch 7, 54-60)

La libertad religiosa entonces, introduce otra variable interpretativa en el proceso de definición del concepto de libertad, pero esta nueva pauta es tendencialmente conflictiva en su dimensión social, porque podría generar peligrosas justificaciones volitivas y constituir una fuente de conflicto, muerte y guerra en contraste con la paz social.

13 Recordamos que la primera persecución de la Iglesia cristiana fue bajo el imperador Nerón y tuvo lugar en el año 67. 
Podemos preguntarnos: ¿El derecho religioso es también libertad para el martirio? ¿Cómo tendría que intervenir el Estado y las Organizaciones internacionales para regular y salvaguardar la vida y la Paz social?

Parece evidente que las justificaciones de las actuaciones coercitivas gubernamentales, tengan que pasar a través del derecho y su reglamentación legislativa nacional e internacional, por eso, recogiendo el artículo 16 de la $\mathrm{CE}$, empezaremos a entrar en los méritos de una perspectiva política de la libertad religiosa.

Sea mencionado cómo el camino de la legislación española hacia el reconocimiento de la libertad humana, haya empezado en 1978 con la garantía constitucional otorgada por el artículo 16, sin embargo, los contenidos específicos del derecho a la libertad religiosa fueron definidos por la Ley Orgánica 7/1980, de libertad religiosa y el artículo 2 es muy significativo porque recoge un amplio radio de acciones humanas que comprenden: la exteriorización del sentimiento del creyente, las prácticas de los actos de culto y de asociación, y la enseñanza religiosa.

La libertad religiosa y de culto garantizada por la Constitución comprende, con la consiguiente inmunidad de coacción, el derecho de toda persona a: a) Profesar las creencias religiosas que libremente elija o no profesar ninguna; $[\ldots]$ abstenerse de declarar sobre ellas. b) Practicar los actos de culto y recibir asistencia religiosa de su propia confesión; [...] c) Recibir e impartir enseñanza e información religiosa de toda índole, ya sea oralmente, por escrito o por cualquier otro procedimiento; $[\ldots]$ d) Reunirse o manifestarse públicamente con fines religiosos y asociarse para desarrollar comunitariamente sus actividades religiosas de conformidad con el ordenamiento jurídico general y lo establecido en la presente Ley Orgánica ${ }^{14}$. [...]

Las consecuencias del artículo 16, en específico por la extensión de la li-

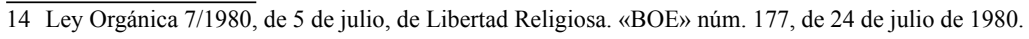


bertad de culto a todos los ciudadanos y la declaración de la aconfesionalidad del Estado ${ }^{15}$ nos conducen a otra interesante cuestión: la definición de un Estado laico en relación con la separación entre Iglesia y Estado español; pero antes de considerar este principio, recogeremos la ocasión para definir las tres tipologías de libertad garantizadas constitucionalmente; en otras palabras, de cómo se concreta la noción de libertad: la libertad ideológica, religiosa y de culto.

\section{Libertad ideológica}

El significado (no filosófico) de ideología, el "conjunto de ideas fundamentales que caracteriza el pensamiento de una persona, colectividad o época, de un movimiento cultural, religioso o político, etc." (Diccionario de la RAE, 2014), nos ayuda en la comprensión de la extensión con la cual las creencias u opiniones humanas pueden exteriorizarse y también, consecuentemente, de su diferenciación con respecto a la libertad de expresión.

La declaración de una idea fundamental que nos caracteriza, la puesta en acto de la libertad ideológica, puede manifestarse hacia el exterior también mediante gestos o actitudes y no necesariamente por medio del lenguaje verbal, como aveces ocurre por la expresión humana. Por ejemplo, tener una bandera colocada en su propio balcón, llevar una camiseta con la imagen de algún personaje histórico, puede representar algún tipo de declaración ideológica.

La posición del Estado español establecida por la CE, no genera ninguna exclusión de ideologías y todas son indiferentemente ${ }^{16}$ admitidas, a pacto del respeto del orden público, pero el posicionamiento imparcial del Estado de cara a las ideologías, no indica que algunas de ellas no puedan ser fa-

\footnotetext{
15 Nos parece interesante recordar que "el apartado $3^{\circ}$ no figuraba en el borrador publicado en la prensa en noviembre de 1977, pero ya sí en el Anteproyecto". Disponible en http://www.congreso.es/ [Consulta: 01/12/2014]

$16 \mathrm{La}$ “'Constitución plasma lo que se conoce como 'indiferentismo ideológico', en el sentido de que admite cualquier tipo de ideología, con el límite del orden público". Disponible en http://www.congreso.es/ [Consulta: 01/12/ 2014].
}

\section{3}


vorecidas (por cierto, nos referimos a los "valores superiores" de libertad, justicia y pluralismo político puestos a primer apartado del art.1 CE).

\section{Libertad religiosa y libertad de culto}

La libertad religiosa y la de culto, aunque se tengan que distinguir, están muy relacionadas entre ellas, constituyen el corolario de la libertad ideológica e introducen al principio de separación entre Iglesia y Estado.

La libertad religiosa a su vez, se distingue de la ideológica principalmente por el ejercicio de su dimensión comunitaria o colectiva, que no perjudica su componente individual y que encuentra su máxima expresión externa mediante los actos de culto.

El fenómeno cultural de las prácticas de culto es una modalidad expresiva muy antigua (probablemente la primera) y su valor, su campo de actuación, se extiende fuera de la dimensión puramente humana, del mundo de los hombres, porque conecta a la dimensión sagrada, al mundo de lo divino, representando una de las máximas exteriorizaciones de la componente espiritual subyacente al "ser hombre". No resulta fácil definir sumariamente el concepto de rito, pero lo haremos recordando las contribuciones de Filoramo, Massenzio, Raveri y Scarpi (2000):

Una definición de carácter meramente orientativo puede ser la siguiente: el rito consiste en una acción o un conjunto de acciones que se sitúan en una dimensión «aparte» respecto de la cotidiana. Desde el punto de vista tipológico, siguiendo el ejemplo de A. Brelich (1966), es posible distinguir dos categorías fundamentales de ritos: la de los ritos «autónomos» y la de los ritos «de culto». Los primeros son eficaces en sí y por sí mismos, a diferencia de los segundos, cuya eficacia está subordinada a la «respuesta» del oponente sobrehumano con el que los propios ritos deben actuar de mediadores. (Por culto hay que entender el sistema de relaciones institucionalizadas 
que existen entre el plano humano y el plano extrahumano; esas relaciones se manifiestan a través del lenguaje de los ritos). (p.361)

Habría mucho que decir acerca del significado del culto y de sus interpretaciones, y un atento estudio nos obligaría a la introducción de otros conceptos religiosos, como el mito, pero este no es el lugar apropiado para hacerlo, ya que su análisis reenviaría a otras tipologías de argumentos; decimos solamente que desde los albores de la humanidad, se han manifestado dos fenómenos culturales cargados de un fuerte gravamen emocional: la práctica de culto y el mito.

La moderna interpretación de los actos de culto y de sus explotaciones mediante rituales, resaltan una función utilitarista; tal corriente de pensamiento se desarrolló gracias a las contribuciones del filólogo y helenista alemán Wilamowitz-Moellendorff:

El objeto del culto con todas sus prácticas es entrar en contacto con el dios y ejercer un cierto influjo sobre él. Esto tiene dos vertientes, o bien se llevan a cabo para ganarse la simpatía y la benevolencia del dios, o bien para conjurar su ira. (1931, p.35, vol. I)

Con las debidas reservas, la interpretación utilitarista podría ser aceptada, ya que no contradice el sentido de conexión con el mundo invisible al cual nos referimos en precedencia a las celebraciones cultuales que constituyen un lenguaje de la presencia divina en el mundo que, en otras palabras, muestra la apertura espiritual humana.

Justamente, se considera ahora el principio de separación entre Iglesia y Estado que aun manteniendo una actitud colaborativa con la Iglesia católica y las demás religiones, se desarticula a partir del tercer apartado del artículo 16 de la CE, y que como veremos en otro capítulo, representa el pilar de la política de la Asociación Internacional para la Defensa de la Libertad Religiosa (AIDLR). 
El Consejo de Europa ${ }^{17}$ también se pronunció sobre la cuestión que concierne a la confesionalidad y a la laicidad del Estado, y a reguardo, el 2 de febrero de 1993, en su recomendación parlamentaria sobre tolerancia religiosa en una sociedad democrática núm. 6, precisaba: «Europa occidental ha elaborado un modelo de democracia laica dentro del cual son toleradas todas las creencias religiosas por principio. La historia ha demostrado que la misma tolerancia puede existir bajo un régimen religioso...» (Carazo Liébana, 2011).

La separación entre los poderes espirituales y los terrenales no es un reciente concepto jurídico-religioso, es bastante antiguo y se remonta al humanismo italiano del siglo XIV, además, se podría decir que el primer texto literario donde se desplegó fue el De Monarchia (1311) de Dante Alighieri, pasando por el Defensor pacis (1324) de Marsilio de Padua y teorizado en El Príncipe (1513) de Nicolás Maquiavelo, como nos recuerda Bermudo (1994):

Macchiavello piensa desde tradiciones muy arraigadas de pensamiento político, no sólo la de Aristóteles, sino la de Polibio, y las de ciertas doctrinas medievales, tanto de escuela gibelina (Dante, Marsilio de Padua) como de la güelfa (Tomas de Aquino y Egidio Colonna). El Defensor pacis es la grande obra política de la Edad Media. En ella se defienden tesis muy modernas, como considerar la soberanía esencia del estado y las leyes condición de su existencia, o defender la separación radical entre iglesia y estado. (p.87)

Es relevante recordar el posicionamiento de Maquiavelo hacia la religión porque su postura parece interesante en vista de una conceptualización del derecho a la libertad religiosa, ya que concibió la religión como instrumen-

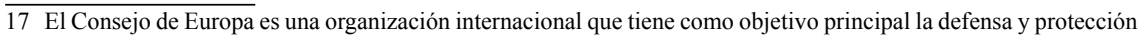
de la democracia, el Estado de Derecho y los derechos humanos, en particular los civiles y políticos. Se trata de la institución de este tipo más antigua de nuestro continente y engloba a la totalidad de las naciones europeas con la sola excepción de Bielorrusia. Tiene su sede en la ciudad francesa de Estrasburgo y su órgano más activo es el Tribunal Europeo de Derechos Humanos. Disponible en http://universitas.idhbc.es/n14/14-04.pdf [Consulta: $03 / 12 / 2014]$. 
tum regni, en otras palabras un 'instrumento de monarquía' o de gobierno, un medio de control de las masas (por parte del Estado o del poder eclesiástico) para conseguir y mantener el poder político, es decir una religión de Estado orientada exclusivamente a la política.

De la teoría a la práctica se pasó oficialmente en el 1648 durante las negociaciones de la paz de Westfalia, el primer congreso diplomático moderno durante el cual nació un nuevo fenómeno y un neologismo, la secularización.

Filoramo nos recuerda:

El término secularización (del lat. saeculum) se usó por primera vez durante las negociaciones de la paz de Westfalia, para denominar el traspaso de bienes o zonas de influencia de la Iglesia a gobernantes laicos [...] un verdadero proceso de expropiación de las competencias eclesiásticas que se adjudicaron a los nuevos estados modernos. (2001, p.518)

\section{EL DERECHO A LA LIBERTAD RELIGIOSA EN EL ÁMBITO EDUCATIVO}

Entre las distintas perspectivas bajo las cuales puede ser interpretado el concepto de libertad, la educativa es sin duda la más fascinante y resolutoria en vista de una conciliación social y religiosa apta al conseguimiento de la paz social y también porque entramos en consideración de los derechos de los "pequeños adultos", los menores de edad. El preámbulo proporciona el art. 26 de la Declaración Universal de los Derechos Humanos:

1. Toda persona tiene derecho a la educación. La educación debe ser gratuita, al menos en lo concerniente a la instrucción elemental y fundamental. La instrucción elemental será obligatoria. La instrucción técnica y profesional habrá de ser generalizada; el acceso a los estudios superiores será igual para todos, en función de los méritos respectivos. 
2. La educación tendrá por objeto el pleno desarrollo de la personalidad humana y el fortalecimiento del respeto a los derechos humanos y a las libertades fundamentales; favorecerá la comprensión, la tolerancia y la amistad entre todas las naciones y todos los grupos étnicos o religiosos, y promoverá el desarrollo de las actividades de las Naciones Unidas para el mantenimiento de la paz.

3. Los padres tendrán derecho preferente a escoger el tipo de educación que habrá de darse a sus hijos.

La definición del derecho a la educación fijada en la DUDH muestra una relevante perspectiva en el concepto de persona, un "ser o entidad capaz de derechos y obligaciones, aunque no tenga existencia individual física, como las corporaciones, asociaciones, sociedades y fundaciones" (Ossorio, s.f., p.721).

Sin embargo, el "derecho preferente de educación" difícilmente podría ser vetado, ya que modificaría los derechos y deberes surgidos por las relaciones paterno-filiales y de la patria potestad. Y además, ¿sería lícito destruir el "derecho a la felicidad" de los padres? ¿No se llega a elegir una educación religiosa para nuestros hijos para ofrecer ellos una esperanza de felicidad añadida?

El "camino legislativo" del derecho a la educación y enseñanza, que también incluye el derecho preferente de los padres, se desarticula según tres grandes etapas: empieza con la formulación del derecho de los padres en el art. 27 de la Constitución, pasa por el reconocimiento en la Ley Orgánica 7/1980, de Libertad Religiosa, y se regula especificadamente por la Ley Orgánica 8/1985 ${ }^{18}$ reguladora del Derecho a la Educación (LODE), donde ya en el Preámbulo se reconoce al valor del derecho a la educación en vista del "progreso social" ("En efecto, el desarrollo de la educación, fundamento del progreso de la ciencia y de la técnica, es condición de bien-

18 Ley Orgánica 8/1985, de 3 de julio, reguladora del Derecho a la Educación. Boletín Oficial del Estado, 159, de 4 de julio de 1985. 
estar social y prosperidad material, y soporte de las libertades individuales en las sociedades democráticas").

El derecho a la educación, a la libertad de enseñanza y a la elección preferente, fue formulado por el art. 27 de la Constitución, además incluyendo entre otros, los propósitos (el desarrollo de la personalidad humana según principios democráticos) y los fundamentos de la enseñanza básica, obligatoria y gratuita; así cantan el primer y el tercer apartado: "Todos tienen el derecho a la educación. Se reconoce la libertad de enseñanza" y "Los poderes públicos garantizan el derecho que asiste a los padres para que sus hijos reciban la formación religiosa y moral que esté de acuerdo con sus propias convicciones".

Una Sentencia del Tribunal Constitucional ${ }^{19}$ de $1981^{20}$ disipa las dudas en el sentido del valor de la libertad de enseñanza reconocida en la Constitución:

La libertad de enseñanza que explícitamente reconoce nuestra Constitución (art. 27.1) puede ser entendida como una proyección de la libertad ideológica y religiosa y del derecho a expresar y difundir libremente los pensamientos, ideas u opiniones que también garantizan y protegen otros preceptos constitucionales (especialmente arts. 16,1 y 20,1 a). Fundamento Jurídico 7 (RTC, 1981\5).

La segunda etapa del camino legislativo mencionado, nos aproxima al derecho a la educación (componente educativa religiosa incluida), y su reconocimiento en la Ley Orgánica 7/1980, de Libertad Religiosa, en particular manera el art. 2. 1c, nos permite hablar de una interesante cuestión, ya que involucra diferentes esferas jurídicas personales llamadas en causa en el proceso educativo de los menores: la de los padres, de los niños y del Estado representado por el enseñante. Por eso "una estructura jurídica algo

19 Cf. Tomás., \& Valiente, F. (1993). Escritos sobre y desde el Tribunal Constitucional, Madrid: Centro de Estudios Constitucionales. El autor habla de los derechos fundamentales como un "mínimo ético asumido democráticamente" p.192.

20 Sentencia del Tribunal Constitucional, STC 005/1981, de 13 de febrero de 1981. Boletín Oficial del Estado, 47, de 24 de febrero de 1981. Fundamento Jurídico 7 (RTC 1981\5). 
compleja" (Martín-Retortillo Baquer, 2008, p.55), un derecho, que bien podríamos llamar "poliédrico" o "multifacético" (Ruano Espina, 2009, p. 2).

En el marco del reconocimiento de los derechos de los padres, y en particular modo en ámbito religioso, el art. 4 de la $L O D E$ es representativo, reconociendo "la formación religiosa y moral que esté de acuerdo con sus propias convicciones"; además de otras participaciones, como por ejemplo "estar informados sobre el progreso del aprendizaje e integración socio-educativa de sus hijos" o las contribuciones "en el proceso de enseñanza y aprendizaje" de su prole, y todas estas declaraciones de derechos-deberes de los padres, se justifican siendo ellos los "primeros responsables de la educación de sus hijos o pupilos".

La regulación legislativa del derecho a la educación, implica la subjetividad de tres personas, una jurídica y dos físicas, las cuales se disponen respectivamente para una interrelación de derechos y deberes:

1) EL ESTADO con su obligación en garantizar el derecho a la educación para todos los ciudadanos; recordamos por ejemplo una de las competencias de los Municipios reglamentada con la Ley $7 / 1985^{21}$ : "participar en la vigilancia del cumplimiento de la escolaridad obligatoria" (art. 25, n). La regularización del sistema educativo por parte del Estado podría permitir a este último ejercer alguna tipología de adoctrinamiento (moral, religioso, filosófico) que podría no ser compartido, o a lo peor rechazado por los padres o los menores.

2) LOS PADRES con los deberes en la educación de su prole y el poderío ejerciendo el derecho preferente derivado por patria potestad. El Código Civil rige la vigente legislación, por ejemplo en el Libro Primero (De las personas) el Título V (De la paternidad y filiación) o el VII (De las

21 Ley 7/1985, de 2 de abril, Reguladora de las Bases del Régimen Local. Boletín Oficial del Estado, 80, de 3 de abril de 1985. Ley que ha sido objeto de numerosas reformas parciales, por Ley 11/1999, de 21 abril; Ley 57/2003, de 16 diciembre; Ley 30/2007, de 30 octubre; Ley 8/2007, de 28 mayo (Ruano Espina, 2009). 
relaciones paterno-filiales), de los cuales recordamos respectivamente el art.110 CE y el art.154 CE.:

El padre y la madre, aunque no ostenten la patria potestad, están obligados a velar por los hijos menores y a prestarles alimentos y la patria potestad comprende los siguientes deberes y facultades: $1^{\circ}$ Velar por ellos, tenerlos en su compañía, alimentarlos, educarlos y procurarles una formación integral. [...]

El término de persona en ámbito legal y una citación de uno de los máximos líderes de la Unión Soviética, crean una curiosa y fortuita imagen, que puede hacernos entender las problemáticas ínsitas en el derecho a la educación: "La cultura es un arma, cuyo efecto depende de qué mano la haya forjado, qué mano la dirija" (Stalin, 2002)22.

3) EL MENOR, poseedor de los mismos derechos de los adultos, titular del derecho a la educación, a la libertad religiosa y de conciencia (Ruano Espina, 2009) se encuentra en una condición especial desde el punto de vista legal, una incapacidad juridicial ${ }^{23}$, siendo los padres que "velan" por sus derechos y bienestar, hasta que haya alcanzado la mayoría de edad ${ }^{24}$ y el art.155 CE dispone los deberes de los hijos: "Los hijos deben: $1^{\circ}$ obedecer a sus padres mientras permanezcan bajo su potestad, y respetarles siempre. $2^{\circ}$ contribuir equitativamente, según sus posibilidades, al levantamiento de las cargas de la familia mientras convivan con ella".

En ámbito internacional los derechos de la infancia, los derechos de los

22 Nos referimos a la entrevista que tuvieron Stalin y H.G. Wells en el 1934. Publicada en España en el Leviatán - Revista Mensual de hechos e ideas (1934-1936): "Una conversación entre Stalin y Wells", Leviatán, núm. 9, enero 1935; además “Comentarios a la conversación Stalin-Wells”, Leviatán, núm. 10, febrero de 1935.

23 Se ve la distinción entre capacidad jurídica y capacidad de obrar. Capacidad jurídica: "La aptitud que tiene el hombre (y la mujer) para ser sujeto o-parte, por sí o por representante legal, en las relaciones de Derecho, ya como titular de derechos o facultades, ya como obligado a una prestación o al cumplimiento de un deber."; Capacidad de obrar: "La capacidad de hecho, el poder de realizar actos con eficacia jurídica (Sánchez Román). Se opone a la capacidad jurídica". (Ossorio, s.f., p.137).

24 Artículo $276 \mathrm{CE}$ : "La tutela se extingue: 1. Cuando el menor de edad cumple los dieciocho años, a menos que con anterioridad hubiera sido judicialmente incapacitado. 2. Por la adopción del tutelado menor de edad. 3 . Por fallecimiento de la persona sometida a tutela. 4. Por la concesión al menor del beneficio de la mayor edad". 
niños y los deberes de los padres, fueron establecidos por $\mathrm{UNICEF}^{25}$ en la Convención de las Naciones Unidas sobre los Derechos del Niño de 20 de noviembre de 1989, empeñando a los Estado en el respecto del "derecho del niño a la libertad de pensamiento, de conciencia y de religión” (art.14.1). De particular resume es la parte restante:

Los Estados Partes respetarán el derecho del niño a la libertad de pensamiento, de conciencia y de religión [...] respetarán los derechos y deberes de los padres $[\ldots]$ de guiar al niño en el ejercicio de su derecho de modo conforme a la evolución de sus facultades. La libertad de profesar la propia religión o las propias creencias estará sujeta únicamente a las limitaciones prescritas por la ley que sean necesarias para proteger la seguridad, el orden, la moral o la salud públicos o los derechos y libertades fundamentales de los demás.

En ámbito nacional, siguiendo una costumbre que se está consolidando en el tiempo, fueron reconocidos en modo más explícito los derechos regulados por la Convención sobre los derechos de los niños, gracias a la Ley Orgánica 1/1996"26, la cual reconoce que "el menor tiene derecho a la libertad de ideología, conciencia y religión ${ }^{27}$ " (Art. 6.1) y recordamos también el art. 30 de la Ley 30/1992 28 , donde en vista del reconocimiento del valor de los derechos inalienables, permite al menor la "capacidad de obrar" en contra de la patria potestad por la defensa de sus derechos: "tendrán capacidad de obrar [...], además [...] los menores de edad para el ejercicio y defensa de aquellos de sus derechos e intereses cuya actuación esté per-

25 Unicef (United Nations Children's Fund), el Fondo de las Naciones Unidas para la Infancia, es la primera organización internacional bajo dependencia de la ONU en la defensa de los derechos de la infancia.

26 Ley Orgánica 1/1996, de 15 de enero, de Protección Jurídica del Menor, de modificación parcial del Código Civil y de la Ley de Enjuiciamiento Civil. Boletín Oficial del Estado, 15, de 17 de enero de 1996.

27 Cf. Asensio Sánchez, M. A. (2006). La patria potestad y la libertad de conciencia del menor. El interés del menor a la libre formación de su conciencia. Madrid: Tecnos; Cf. Moreno Antón, M. (2007). Multiculturalidad y libertad religiosa del menor. Madrid: Fundación Universitaria Española; Cf. Puente Alcubilla, V. (2001). Minoría de edad, religión y Derecho ( $1^{\mathrm{a}}$ ed.). Madrid: Ministerio de Trabajo y Asuntos Sociales; Cf. Rodrigo Lara, B. (2005). Minoría de edad y libertad de conciencia. Madrid: Servicio de Publicaciones de la Facultad de Derecho (Universidad Complutense de Madrid); (Ruano Espina, 2009, p.8). Cf. Rodrigo Lara, B. (2005). Minoría de edad y libertad de conciencia. Madrid: Servicio de Publicaciones de la Facultad de Derecho (Universidad Complutense de Madrid).

28 Ley 30/1992, de 26 de noviembre, de Régimen Jurídico de las Administraciones Públicas y del Procedimiento Administrativo Común. Boletín Oficial del Estado, 285, de 27/11/1992. 
mitida por el ordenamiento jurídico-administrativo sin la asistencia de la persona que ejerza la patria potestad, tutela o curatela".

La enseñanza institucionalizada, es decir, la regulación del sistema educativo por parte del Estado, podría generar unos peligrosos desencuentros y sospechas de manipulación ideológica entre tres frentes, los cuales representan la dos distintas tipologías de personas mencionadas: en otras palabras, una oposición entre los valores educativos del Estado, aquellos de los padres elegidos para los hijos y también aquellos de estos últimos, futuros individuos de conciencia independiente.

Principalmente, aunque se reconozca al menor el derecho para hacer valer ciertos de sus derechos también en contra de la patria potestad, la fuente de posibles choques se da en torno al Estado y los padres.

La transmisión de valores es intrínseca a la educación (y también lo son las diferencias/controversias) y enlaza con problemáticas de tener en cuenta: por un lado el Estado, pudiendo elegir los contenidos curriculares, podría condicionar el desarrollo cognitivo de sus ciudadanos, y por el otro lado, los padres podrían no compartir los ideales transmitidos a sus hijos y estos últimos también, ¿no tendrían derecho en elegir su educación, su religión?

Por todas estas preocupaciones, entendemos cómo ha tenido que ser constitucionalizada la neutralidad ideológica de los centros públicos y hecho respetar el derecho preferente de los padres.

Dos Sentencias del Tribunal Supremo del 24 y 30 de junio de 1994, hacen luz sobre estos confusos asuntos, iluminando acerca de la comprensión del art. 27.3 CE y de la modalidad con la cual se hace respetar el derecho de los padres en educar los hijos según sus principios ideológicos de pertenencia: diferenciando dos tipologías de protecciones, el derecho de protección directa y el derecho de protección indirecta. "No es un derecho 
de protección directa, porque, como se comprenderá, los poderes públicos no pueden garantizar que en todos y cada uno de los puntos del territorio nacional existan colegios o centros de enseñanza que respondan a las preferencias religiosas y morales de todos y cada uno de los padres españoles" (STS, 5278/1994 de 24 junio 1994, FJ7).

Entonces esto significa que la protección es indirecta; en otras palabras, "que se consigue a través del establecimiento y protección de otros derechos constitucionales", como el derecho a la libertad de enseñanza, a la creación de centros docentes y a la libertad de cátedra, pero también por medio del reconocimiento de la neutralidad ideológica de los centros docentes públicos (Ruano Espina, 2009, p.11). Resumimos el Fundamento Jurídico $7^{\circ}$ de la Sentencia de 24 de junio de 1994:

El artículo 27.3 de la Constitución [...] dispone que «los poderes públicos garantizan el derecho que asiste a los padres para que sus hijos reciban la formación religiosa y moral que esté de acuerdo con sus propias convicciones». Ahora bien, éste no es un derecho de protección directa [...] Se trata, en consecuencia, de un derecho de protección indirecta, que se consigue a través del establecimiento y protección de otros derechos constitucionales [...] y la neutralidad ideológica de los centros públicos [artículo 18-1 de la Ley Orgánica 8/1985, de 3 julio (RCL 1985\1604, 2505 y ApNDL 4323), reguladora del derecho a la educación]. [...] sin necesidad, por lo tanto, de que exista una regulación propia, específica y concreta del mismo (STS, 5278/1994 de 24 junio 1994, FJ7).

La influencia católica en la política de los Estados (no es relevante que este último se reconozca laico y aconfesional.... siempre queda el derecho a expresarse), antes o después no se deja atender también en España. Recordamos la intervención del cardenal Rouco Varela en una conferencia pronunciada el 29 de mayo de 2007 cuando, censurando la asignatura de 
Educación para la Ciudadanía, amonesta al gobierno ${ }^{29}$ por incluir una disciplina dirigida a la formación moral de los alumnos, la cual subintroduce "a través de los presupuestos antropológicos explícitos e implícitos de dicha asignatura, una concepción del hombre, de la vida y del mundo que equivalga a una doctrina o ideología obligatoria que venga de hecho a competir con la formación religiosa elegida libremente o a suplantarla subrepticiamente. La conclusión es válida naturalmente tanto para la escuela pública como para la privada o de iniciativa social" (Rouco Varela, 2007, p.385).

Abriremos un paréntesis considerando los informes PISA ${ }^{30}$. Aunque parezcan en primer análisis poco pertinentes, pensamos que pueden mostrar una interesante perspectiva (aunque no satisfactoria) en vista de una "educación a la paz". ¿Por qué si los consideramos como marco de evaluación del nivel de escolarización obligatoria española los resultados no son halagadores?

Antes de todo recordamos el último del año 2012:

España tiene mejor rendimiento en matemáticas, lectura y ciencia que en resolución de problemas. Con una puntuación media de 477 puntos, España se sitúa por debajo del rendimiento académico medio de la OCDE y ocupa entre las posiciones 27 y 31 respecto al total de los 44 países y economías que participaron en la evaluación de la resolución de problemas (Resultados PISA 2012. Resolución de problemas. España).

Al empezar el parágrafo, se han expuesto nuestras consideraciones sobre la importancia del derecho a la educación y de la libre enseñanza, en la perspectiva de una conciliación social y religiosa; sin embargo, acabamos de

29 Véase también el artículo de El Mundo.es-España de 1 de junio de 2007, "Rouco Varela tacha de inconstitucional la asignatura de Educación para la ciudadanía".

30 PISA (Programme for International Student Assessment), el Programa para la Evaluación Internacional de Alumnos: "es una encuesta trienal que evalúa el grado en el que el alumnado de 15 años de edad -próximos a finalizar la educación obligatoria- han adquirido los conocimientos y destrezas que son esenciales para la plena participación en las sociedades modernas. La evaluación no se limita a determinar si los alumnos pueden reproducir conocimientos, sino que también examina la forma en que los estudiantes pueden extrapolar a partir de lo que han aprendido y aplicar ese conocimiento en entornos desconocidos, tanto dentro como fuera del centro educativo". (Resultados PISA 2012 - Resolución de problemas. España). 
mencionar los resultados del último informe PISA. ¡Podría sorprender la manera en que los dos estén relacionados! ¿Cómo puede ser comprometida la paz social por unas notas negativas en la "resolución de problemas"?

Es importante; si se presta atención a la definición de competencia de resolución de problemas, mencionada en el mismo informe, se pueda entender la pregunta:

(...) la capacidad de un individuo para participar en los procesos cognitivos para comprender y resolver situaciones problemáticas en las que un método de solución no es inmediatamente obvio. Incluye la disposición a comprometerse con este tipo de situaciones con el fin de alcanzar su potencial como ciudadano constructivo y reflexivo.

¿Los pueblos del futuro no serán formados por ciudadanos "constructivos y reflexivos"? Es decir, ¿las próximas generaciones serán intolerantes? ¿Y si algunos padres, preocupados por la calidad ${ }^{31}$ de la escolarización obligatoria y gratuita, no queriendo o pudiendo valerse de escuelas privadas, quisieran ocuparse personalmente de la educación escolar de sus hijos?

La solución nos la da una reciente Sentencia del Tribunal Constitucional Español (2010), la cual ilegalizó la práctica de la educación en el hogar. Recogemos la noticia por fuente periodística (El País, online):

La Sala primera del Tribunal Constitucional ha denegado a unos padres la posibilidad de formar a sus hijos en su propio domicilio sin escolarizarlos en un centro oficial. Según la sentencia, la Constitución no prohíbe que se defina un sistema de enseñanza básica obligatoria, considerado "como un período de escolarización de duración determinada", pero durante dicho período queda excluida la posibilidad de enseñar a los hijos en el domicilio familiar en lugar de escolarizarlos ${ }^{32}$. (Lázaro, J.M.)

31 La calidad de la educación es un derecho reconocido por la Ley Orgánica 8/1985 reguladora del Derecho a la Educación: "[...] reciban una educación, con la máxima garantía de calidad [...]" (Art.4.1a).

32 Disponible en http://elpais.com/elpais/2010/12/16/actualidad/1292491045_850215.html [Consulta: 22/01/2015]. 
¡No se tendría que estar equivocado definiendo el derecho a la educación como "poliédrico" o "multifacético"! Es necesario, en vista de una comprensión del derecho a la libertad religiosa en el ámbito educativo, el análisis del derecho a la educación, ya que su contextualización implica dos extensiones de sumaria importancia: por un lado muestra la importancia de la educación en la formación de ciudadanos respetuosos de los derechos de los demás, a la cual se suma la problemática de la interrelación de derechos entre tres distintas personas, el Estado, los padres y el menor.

La coparticipación extensa de derechos formalizada en esta triple interconexión, nos permite comprender mejor el valor de la dimensión del derecho a la libertad religiosa en perspectiva educativa, y la componente que en nuestra opción parece más interesante, es decir, el derecho preferente de educación, "el derecho de los padres a elegir para sus hijos la educación religiosa y moral conforme a sus convicciones". Ruano Espina (2009, p.9), abre el camino a interesantes debates y constituye un componente fundamental en el ordenamiento de un sistema educativo civil, ya que además, podría generar contrastes ideológicos.

En este sentido y para terminar, se considera oportuno prestar atención a Italia, recordando un caso legal que tuvo relevancia política internacional, ejemplar en la comprensión de los contrastes ideológicos en ámbito educativo-religioso: Lautsi vs. Italia, conocida en el "bel paese" como "la controversia del crucifijo en las aulas".

Por consiguiente, se considera que toda vicisitud pueda ser considerada como modelo representativo de los contrastes que se generan en el seno a la libertad de expresión religiosa, reconociendo en el caso italiano unos valores añadidos respecto a lo ocurrido en el análogo caso alemán ${ }^{33}$, ya que

33 Sentencia BVerfGE 93, 1, de 16 de mayo de 1995. Recordamos la Sentencia del Tribunal Federal Constitucional (BVG) alemán, el cual, en 1995, declaró la inconstitucionalidad del crucifijo en las aulas escolásticas generando tensiones sociales vueltas en contra de la decisión tomada. Véase, Comas, J. (1995, 09, 13). "Baviera inicia el curso con el crucifijo en las aulas pese a ser inconstitucional". El País Archivo. Disponible en http://elpais.com/ diario/1995/09/13/sociedad/810943204_850215.html [Consulta: 12/01/2015]. 
la influencia de la Iglesia católica en los asuntos laicos de un Estado, sea mayor en Italia respecto que a otros países sólo por la proximidad del Vaticano.

La controversia ideológico-política se remonta al 22 de abril de 2002, cuando Massimo Albertin, marido de Soile Lautsi, una ciudadana italiana de origen finlandés, durante un Consejo Escolar del Instituto "Vittorino da Feltre", una escuela pública del Véneto, solicitó la remoción del crucifijo colgado a la pared de las aulas, donde sus hijos menores tenían clase. Por lo visto, esta costumbre vigente en las escuelas públicas italianas es tan arraigada que no tiene que extrañar la contestación a la solicitud: el Consejo decidió por diez votos contra dos, y una abstención, mantener los símbolos en las aulas escolares.

La odisea legal de la familia Albertin empezó en los tribunales italianos competentes, es decir, el TAR, donde doña Lautsi recurrió la decisión del Consejo Escolar aduciendo la violación del principio de laicidad del Estado: "apoyándose en la conexión del artículo 3 (principio de igualdad) y 19 (principio de libertad religiosa) de la Constitución Italiana, así como el artículo 9 del Convenio y el principio de imparcialidad de las autoridades de la administración pública (artículo 97 de la Constitución italiana)" (Trejo Osornio, 25/04/2011).

El TAR, después de dos años, en el 2004, decidió suspender el juicio ${ }^{34}$ trasladándolo al Tribunal Constitucional, el cual por su parte, irónicamente y apropiadamente podemos decir que "se lavó las manos 35 ", en términos jurídicos: se declaró no idóneo para discutir el caso $^{36}$ vista la ausencia de una ley que imponga el crucifijo en las aulas, decidiendo reenviar el contencioso de natura administrativa al remitente.

34 TAR Véneto, Sección I, Ordenanza n. 56/04, de 14 enero de 2004

35 Nos referimos a la postura de Poncio Pilato, quinto prefecto de la provincia romana de Judea, el cual, a igual manera que el Constitucional Italiano, prefirió no entrar en méritos de cuestiones religiosas: "Y viendo Pilato que nada adelantaba, sino que se hacía más alboroto, tomó agua y se lavó las manos delante del pueblo, diciendo: Inocente soy yo de la sangre de este justo. ¡Allá vosotros!" (Mt 27,24).

36 Corte Constitucional, Ordenanza n. 389/04, de 15 diciembre de 2004. 
El TAR del Véneto denegó la apelación de doña Lautsi, resumiendo en favor de la presencia del crucifijo en las escuelas públicas; creemos oportuno citar una parte de la Sentencia ${ }^{37}$ para comprender el sentido de los contrastes que se generan en el seno a la libertad de expresión religiosa, así que, libremente traducido del italiano:

Se puede entonces sostener que, en la realidad social actual, el crucifijo debe ser considerado no solamente como símbolo de una evolución histórica y cultural, y por eso de la identidad de nuestro pueblo, sino también como símbolo de un sistema de valores de libertad, igualdad, dignidad humana y tolerancia religiosa y por lo tanto también de la laicidad del Estado, principios que inervan nuestra Carta constitucional. En otras palabras, los principios constitucionales de libertad tienen muchas raíces y una de estas indudablemente es el cristianismo, en su misma esencia. Sería desde luego sutilmente paradójico excluir un signo cristiano de una estructura pública en nombre de una laicidad, que tiene ciertamente una de sus fuentes lejanas precisamente en la religión cristiana. (11.9)

En otros términos: si la esencia del cristianismo es la libertad representada por el símbolo de la cruz, y la esencia de la laicidad estatal es la libertad (constitucionalizada), entonces la remoción de la cruz (cristiana) en nombre de la laicidad del Estado, es también remoción del símbolo de libertad, igualdad, dignidad humana y tolerancia religiosa puestos en los fundamentos constitucionales.

No entraremos en mérito del análisis del texto seleccionado, pero la lógica desarticulada no es tan estrafalaria como pueda superficialmente parecer: hay verdades en los argumentos expuestos por el TAR del Véneto y hemos hablado anteriormente de la nueva libertad cristiana, dimensión interpretativa introducida por Jesucristo.

37 TAR Véneto, Sección III, Sentencia n. 1110/05, de 17-22 de marzo de 2005. Disponible en http://www.uaar.it/ uaar/campagne/scrocifiggiamo/41.html [Consulta: 12/11/2014]. 
Volvemos a la controversia del crucifijo en las aulas escolares. Lautsi decidió apelar la Sentencia ante el "Consiglio di Stato" (Tribunal Supremo Administrativo), el cual el 13 de abril de 2006, confirmó el Dictamen del TAR véneto, reconociendo la compatibilidad entre la presencia de crucifijos en las escuelas públicas y el principio de laicidad del Estado.

El asunto Lautsi vs. Italia fue llevado por la demandante al Tribunal Europeo de Derechos Humanos (TEDH) ${ }^{38}$, el cual tuvo que analizar si Italia infringía el derecho a la educación ${ }^{39}$, el derecho a la libertad de pensamiento, conciencia y religión ${ }^{40}$ y el principio de no-discriminación ${ }^{41}$.

La demanda ${ }^{42}$ fue admitida en 2009 por unanimidad de votos, declarando en contra de Italia por dos de las tres infracciones analizadas y obligándola al resarcimiento por daños morales a favor de la demandante:

POR ESTOS MOTIVOS, EL TRIBUNAL UNÁNIMEMENTE, 1.Declara la demanda admisible; 2. Declara que hubo violación del artículo 2 del Protocolo $\mathrm{N}^{\mathrm{o}}$.1 examinado juntamente con el artículo 9 del Convenio; 3. Declara que no ha lugar al examen de la vulneración del artículo 14 tomado aisladamente o en combinación con el artículo 9 del Convenio y el artículo 2 del Protocolo $\mathrm{N}^{\mathrm{o}} .1 ; 4$. Declara a) que el Estado debe pagar a la demandante, $[\ldots] 5000 €$ (cinco mil euros), por daño moral, [...] (Sentencia de 3 de noviembre de 2009 - Demanda n. 30814/06).

La odisea jurídica empezada por la familia Albertin-Lautsi en 2002 llega casi a final de 2009 a una resolución favorable; en otras palabras, se estaba

38 El Tribunal Europeo de Derechos Humanos (TEDH), también denominado Tribunal de Estrasburgo y Corte Europea de Derechos Humanos, es la máxima autoridad judicial para la garantía de los derechos humanos y libertades fundamentales en el marco del Convenio de Roma de 1950.

39 Garantizado por el art.2 del Protocolo núm. $1 \rightarrow$ Protocolo Adicional al Convenio para la Protección de los Derechos Humanos y de las Libertades Fundamentales, de 20 de marzo de 1952. (Publicado en España en BOE n. 11, de 12 de enero de 1991)

40 Consagrado en el artículo 9 del Convenio Europeo.

41 Asegurado por el art.14 del Convenio Europeo: "El goce de los derechos y libertades reconocidos en el presente Convenio ha de ser asegurado sin distinción alguna, especialmente por razones de sexo, raza, color, lengua, religión, opiniones políticas u otras, origen nacional o social, pertenencia a una minoría nacional, fortuna, nacimiento o cualquier otra situación".

42 Tribunal Europeo de Derechos Humanos, Sección II, Sentencia de 3 de noviembre de 2009 (Demanda n. 30814/06). 
indirectamente reconociendo la inconstitucionalidad del crucifijo en las escuelas públicas de Italia.

La oposición del Estado italiano, sin embargo no tuvo que hacerse esperar y la sentencia fue apelada y sorprendentemente revocada, con los méritos (o deméritos, según perspectiva) de haber conseguido que otros 10 países europeos ${ }^{43}$ se pusieron a favor de la apelación italiana.

La Gran Sala, el Tribunal de Justicia que forma parte del TEDH, el 18 de marzo de 2011 puso término al "asunto Lautsi vs. Italia", declarando ${ }^{44} \mathrm{el}$ fallo de la sentencia anterior con una decisión definitiva e inapelable, la cual obtuvo 15 votos a favor y 2 en contra: Italia ahora (y definitivamente), no violaría el derecho a la educación o a la libertad de conciencia y religión, manteniendo los crucifijos en la escuela pública. La decisión tomada,

Como bien dice Rafael Navarro-Valls, esto es poco frecuente, más aun cuando la Sentencia revocada fue adoptada por unanimidad. Igualmente sucedió algo insólito en el contexto procesal europeo: diez Estados miembros del Consejo de Europa solicitaron intervenir en el proceso como "terceros interesados", lo cual les permitió intervenir con alegaciones orales y escritas (todos los Estados que intervinieron lo hicieron en contra de la Sentencia de la Sección ${ }^{45}$ ).

El malestar por el volcado de la Sentencia favorable, fue expresado por la familia Albertin por medio de un comunicado ${ }^{46}$, donde se denuncia una realidad italiana desconocida a los demás y que demasiadas veces se manifiesta por "l'omertà" (la ley del silencio y de la complicidad).

43 Los gobiernos de Armenia, Bulgaria, Chipre, Federación Rusa, Grecia, Lituania, Malta, Mónaco, Rumania y la República de San Marino.

44 Sentencia del Tribunal de Justicia (Gran Sala), de 18 de marzo de 2011. Disponible en https://aicismo.org/data/ docs/archivo 1545.pdf [Consulta: 20/04/2015].

45 Disponible en http://eljuegodelacorte.nexos.com.mx/?tag=rafael-navarro-valls [Consulta: 20/04/2015].

46 Albertin M., \& Lautsi, S. (s.f.). Comunicato della famiglia Albertin (en italiano e inglés). Disponible en http:// humanistfederation.eu/ckfinder/userfiles/files/NEWS-FHE/2011/513-Comunicato-della-famiglia-Albertin.pdf [Consulta 08/06/2016]. 
[...] La presión política por parte de las organizaciones religiosas es aún muy fuerte $[\ldots]$ tras las sentencias de los tribunales italianos [...] habíamos entendido cuánto la justicia de este Estado sea súcubo del Vaticano y de los tentáculos que sabe extender en nuestra sociedad civil: desde la política a la escuela, a partir de las funciones públicas hasta los tribunales. Sin embargo no pensábamos que el cáncer que consume a Italia hubiera transmitido sus metástasis también a Europa [...] No esperábamos que en la sentencia hubieran imprecisiones y falsedades como cuando se dice: "según el Gobierno italiano el espacio escolar está abierto a otras religiones" o "el fin del Ramadán es a menudo celebrado en las escuelas" [...] El crucifijo es solamente un signo exterior, símbolo prevaricador y opresivo de una práctica difundida y continuada de proselitismo religioso que en nuestras escuelas se da en las modalidades más variadas $[\ldots]$

\section{CONCLUSIONES}

Se ha intentado dar una aproximación a un concepto muy extenso y de difícil definición que abarca diferentes esferas humanas, ocupándonos con particular atención de la específica vertiente religiosa y en la perspectiva de los derechos humanos en vista del conseguimiento de la paz. A excepción podemos observar que los derechos humanos son hoy en día el fervor de nuestro tiempo. Y por su perspectiva cardinal que la tiene dentro de los derechos humanos. No obstante, la libertad religiosa es un derecho fundamental, en consideración la humanidad no confiere una especial atención a la religión. La dificultad de la libertad religiosa o de creencia, a pesar de su larga historia jamás ha gozado de un respeto mayoritario, es ahora donde se enfrentan nuevos desafíos. La complejidad ínsita en la interpretación y definición del concepto de libertad dificulta la posibilidad de minimizar los términos, no permitiendo una simple y mínima definición, y obliga a consideraciones amplias. ¿Qué debería predominar: la libertad, la paz o la seguridad? 
Jamás debería alarmarnos defender una religión o creencia, es necesario salvaguardar la dignidad y el Principio a la libertad de conciencia, libertad religiosa y de expresión. Como señalan las organizaciones no gubernamentales, es necesario excluir los elementos que colocan en riesgo la paz y la democracia: la violencia, el racismo, la xenofobia, el fundamentalismo, las violaciones de los derechos humanos, la intolerancia religiosa, el terrorismo.

El caso Lautsi ha prestado ahora controversias en diversos países, con la presencia de símbolos religiosos en escuelas y hospitales. Podemos mencionar Austria, Suiza, España, Rumania, Perú, entre otros. En el caso de Austria y Perú resolvieron que dichos símbolos no iban en contra de la Constitución. Algo muy trascendente es el apoyo de veinte países en apoyo de Italia y que el Cristianismo sigue teniendo vigencia en toda Europa.

\section{REFERENCIAS BIBLIOGRÁFICAS}

Albertin M., y Lautsi, S. (s.f.). Comunicato della famiglia Albertin (en italiano e inglés). disponible en http://humanistfederation.eu/ckfinder/ userfiles.f.iles/NEWS-FHE/2011/513-Comunicato-della-famiglia-Albertin.pdf [Consulta 08/06/2016].

Asensio Sánchez, M.A. (2006). La patria potestad y la libertad de conciencia del menor. El interés del menor a la libre formación de su conciencia. Madrid, España: Tecnos.

Audi, R. (2004). Diccionario Akal de Filosofia. Trad. Huberto Marraud y Enrique Alonso, Madrid, España: Ediciones Akal. (Obra original publicada en 1995).

Bermudo J. M. (1994). Maquiavelo, consejero de príncipes. Barcelona España: Universidad de Barcelona.

Bobbio, Matteucci. y Pasquino (2005). Diccionario de política (14a ed.), vol. 1, 2. México: siglo xxi editores (Obra original publicada en 1976). Bobbio, N. (2011). Giusnaturalismo e positivismo giuridico ( $2^{\mathrm{a}} \mathrm{ed}$.). Italia: Editori Laterza (Obra original publicada en 1965). 
Carazo Liébana, M.J. (2011). El derecho a la libertad religiosa como derecho fundamental. Universitas. Revista de Filosofia, Derecho y Politica, (14), 43-74. Disponible en http://universitas.idhbc.es/n14/14-04. pdf [Consulta: 02/12/2014].

Carrillo Salcedo, J. A. (1976). Soberanía del Estado y Derecho Internacional, Madrid, España: Tecnos, pp.365-385.

Comas, J. (1995, 09, 13). "Baviera inicia el curso con el crucifijo en las aulas pese a ser inconstitucional". El País Archivo. Disponible en http://elpais.com/diario/1995/09/13/sociedad/810943204_850215.html [Consulta: 12/ 01/ 2015].

Dobbelaere, k. (1981). Secularization: a multi-dimensional Concept, 29(2), Universidad Iberoamericana, London. Trad. Eduardo Sota García, Se-

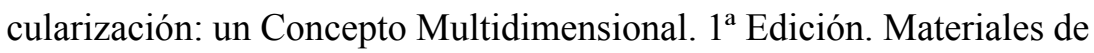
Cultura y religión, Madrid, España: Universidad Iberoamericana, 1994. Ferrater Mora, J. (1958). Diccionario de Filosofía (5 ${ }^{\mathrm{a}}$ ed.) - II Tomos. Argentina: Editorial Sudamericana (Obra original publicada en 1941).

Filoramo, G. (2001). Diccionario Akal de las Religiones.trad. María Teresa Robert Rogla, Madrid, España: Ediciones Akal. (Obra original publicada en 1993).

Filoramo, Massenzio, Raveri, y Scarpi (2000). Historia de las Religiones (Trad. Maria Pons), Barcelona, España: Crítica. (Obra original publicada en 1998).

Iraburu, J. M. (2003). El martirio de Cristo y de los cristianos. Pamplona, España: Fundación Gratis Date. Disponible en http://www.gratisdate.org/nuevas/martirio-jmi/martirio-jmi-default.htm [Consulta: $13 / 11 / 2014]$.

Ley 30/1992, de 26 de noviembre, de Régimen Jurídico de las Administraciones Públicas y del Procedimiento Administrativo Común. Boletín Oficial del Estado, 285, de 27/11/1992.

Ley 7/1985, de 2 de abril, Reguladora de las Bases del Régimen Local. Boletín Oficial del Estado, 80, de 3 de abril de 1985. Ley que ha sido objeto de numerosas reformas parciales, por Ley 11/1999, de 21 abril;

\section{4}


Ley 57/2003, de 16 diciembre; Ley 30/2007, de 30 octubre; Ley 8/2007, de 28 mayo.

Ley Orgánica 1/1996, de 15 de enero, de Protección Jurídica del Menor, de modificación parcial del Código Civil y de la Ley de Enjuiciamiento Civil. Boletín Oficial del Estado, 15, de 17 de enero de 1996.

Ley Orgánica 7/1980, de 5 de julio, de Libertad Religiosa. «BOE» núm. 177, de 24 de julio de 1980.

Ley Orgánica 8/1985, de 3 de julio, reguladora del Derecho a la Educación. Boletín Oficial del Estado, 159, de 4 de julio de 1985.

Ossorio, M. (s.f.). Diccionario de Ciencias Jurídicas Políticas y Sociales ( $1^{\text {a }}$ Edición Electrónica). Honduras: Editorial Datascan. Disponible en http:/elderechoyelestudiante.bligoo.es/media/users/34/1723250/ files/649683/Manuel_Ossorio.pdf [Consulta: 03/02/2015].

Montesquieu (1906). El espiritu de las leyes. Madrid, España: Librería general de Victoriano Suárez. (Obra original publicada en 1747).

Martín Retornillo Baquer, L. (2008). Los padres tendrán derecho preferente a escoger el tipo de educación que habrá de darse a sus hijos. (Un estudio de Jurísprudencia del Tribunal Europeo de Derechos Humanos) Zaragoza, España: El Justicia de Aragón.

Moreno Antón, M. (2007). Multiculturalidad y libertad religiosa del menor. Madrid, España: Fundación Universitaria Española;

Cf. Puente Alcubilla, V. (2001). Minoría de edad, religión y Derecho $\left(1^{\mathrm{a}}\right.$ ed.). Madrid: Ministerio de Trabajo y Asuntos Sociales.

RAE (2014). Diccionario de la Real Academia Española

Resultados Pisa (2012). Programa para la evaluación internacional de alumnos (PISA). Resultados PISA 2012-Resolución de problemas. Recuperado de: http://www.oecd.org/pisa/keyfindings/PISA-2012-PS-results-esp-SPAIN.pdf [Consulta: 15/04/2017]

Rodrigo Lara, B. (2005). Minoría de edad y libertad de conciencia. Madrid, España: Servicio de Publicaciones de la Facultad de Derecho (Universidad Complutense de Madrid); (Ruano Espina, 2009).

Ropero, A. (2010). Mártires y Perseguidores. Historia general de las perse-

\section{5}


cuciones (siglos I-X). Barcelona, España: Clie

Rouco Varela, A.M. (2007). La educación para la ciudadanía. Reflexiones para la valoración jurídica y ética de una nueva asignatura en el sistema escolar español. Disponible en http://www.racmyp.es/docs/anales/A84/ A84-21.pdf [Consulta: 08/06/2014].

Ruano Espina, L. (2009). El derecho a elegir en el ámbito escolar la educación religiosa y moral que esté de acuerdo con las propias convicciones, en el marco de la LOLR. Revista General de Derecho. Recuperado de: http://www.unav.edu/matrimonioyfamilia/b/EC/Ruano_derechoaelegir.pdf [Consulta:12/06/2017].

Sentencia del Tribunal Constitucional, STC 005/1981, de 13 de febrero de 1981. Boletín Oficial del Estado, 47, de 24 de febrero de 1981. Fundamento Jurídico 7 (RTC 1981\5).

STS,5278/1994 de 24 de junio 1994, FJ7: Tribunal Supremo (Sala de lo Contencioso-Administrativo, Sección 3a). Sentencia de 24 de junio 1994 RJ 1994\5278

Tomás., y Valiente, F. (1993). Escritos sobre y desde el Tribunal Constitucional. Madrid, España: Centro de Estudios Constitucionales.

Trejo Osorio, L. A. (25/04/2011). "Lautsi Vs. Italia: el caso del crucifijo en las escuelas, o sobre ¿Qué pasó en el Tribunal Europeo de Derechos Humanos?" Asociación de Analistas de Doctrina Constitucional (ADOC). Recuperado de: http://analistastc.com/2011/04/25lautsi/ [Consulta: 22/05/2017]

Wilamowitz, M., Von U. (1931). Der Glaube der Hellenen (Vols. II). Alemania:Weidmannsche buchhandlung. Disponible en https:/archive. org/details/MN40017 ucmf:O [Consulta: 22/05/2017].

Cómo citar este capítulo:

Pabón-Medina, D.J. (2017). Libertad religiosa, educación y menores de edad. En Albornoz-Arias, N., Mazuera-Arias, R., Espinosa-Castro, J.F. (Ed.), Adolescencia: su relación con la familia, educación y sexualidad. Un enfoque transdisciplinario (pp.207-246). Barranquilla, Colombia: Ediciones Universidad Simón Bolívar. 